\title{
水稻种植中的抗病技术要点分析
}

\author{
崔建磊 \\ 黑龙江北大荒农业股份有限公司八五四分公司 \\ DOI:10.32629/as.v3i3.1850
}

\begin{abstract}
[摘 要] 粮食安全至关重要, 基于我國的人口数量众多、粮食供给量巨大的现状, 为满足人们的正常生活 需要, 水稻需求量不断的增加, 水稻种植呈现逐年递增趋势, 为稳定粮食生产作为工作重心与基础,充分开 展农技推广工作。抗病技术已成为水稻种植中不可缺少, 应因地制宜, 做好再生稻的品种篮选、试验示范 和推广工作,协同科研部门,加强水稻轻简栽培与病虫害防治技术, 全面保障水稻种植的质量, 提升水稻的 生产产量。
\end{abstract}

[关键词] 水稻; 种植; 抗病; 技术

中图分类号: S157.4+33 文献标识码: A

\section{1 水稻种植抗病技术的意义}

良好的抗病技术对水稻病害防治将 发挥重要作用, 能确保水稻良好的病害 抵抗力, 将病害对水稻生长的影响实现 有效的控制, 促进水稻颗粒饱满, 提高水 稻产量和质量, 实现水稻种植的经济收 益。通过抗病技术来进行水稻新品种的 培育, 也能够有效的提高水稻品种的抗 病性, 使其在后期的生长中具有对病害 良好的抗病性, 减少病害影响, 提升水稻 的生产产量。因此, 在水稻种植中一定要 重视抗病技术应用, 提高水稻产量与质 量, 实现对水稻病害的有效控制。

\section{2 水稻种植中的抗病技术要点} 分析

2. 1选种抗病处理

\subsection{1选种}

种子的高质量也能够保证其质量和 产量的提高, 这就需要对选种工作进行 重视。在我国, 诸多地区都适合水稻种植, 不同地区气候环境以及自然条件都存在 一定的差异性, 这对水稻生长也会产生 影响, 只有选择与正常环境相适应的品 种才能够充分促进水稻生长, 这对水稻 的后期生长具有重要的作用, 抗病技术 在选种阶段的应用, 能够有效提升种子 的抗病害性, 为水稻后期健康生长奠定 良好的基础。因此, 要选择稳定性好、耐 寒性强、适应性广、抗病性高的优质水
稻品种。在选种阶段, 要和当地地区实际 情况进行结合来选择水稻品种, 证种子 对当地土壤以及气候特点等具有良好适 应性, 有效控制病害。

\subsection{2种子处理}

水稻种子选择完成后, 需要通过药 物对种子进行浸泡, 使水稻种子于种植 的初级就能够具有良好抗病性, 在对种 子进行药物浸泡中, 药液一般使用的是 $20 \%$ 三环唑的 800 倍液类型, 把种子在其 倍液中进行 $1 \sim 2 \mathrm{~d}$ 的浸泡。而在水稻的 育种阶段, 可以通过杂交技术来进行水 稻新品种的获取, 新品种的抗病能力就 会得到提升, 进而提升其水稻的质量与 产量。

\section{2 种植管理}

在水稻种植中, 科学合理的种植管 理也是降低水稻病害的有效措施, 如在 水稻的纹枯病防治中, 需要对种植地严 格科学的进行管理, 要每天对稻田实施 排查, 对水稻的叶片以及茎干健康性进 行仔细的观察和掌握, 对稻田内存在的 杂物及时有效的进行清除, 这样就能够 保证稻田具有良好的水质, 就能够对病 菌生存环境的控制, 减少稻田菌群的数 量, 同时水稻种植中还可以采取适当 密植方式, 不仅能够对纹枯病进行有 效防治, 还能够实现对水稻产量的有 效提升。

\section{3 水肥管理}

水稻种植的肥水管理也能够有效的 实现对病害的控制。在水稻种植肥水的 管理阶段, 主要是通过对肥水内病菌进 行控制, 来避免其病菌对水稻的幼苗进 行感染。施肥是肥水管理的重难点部分, 施肥作业要确保废料养分具有适量性, 对施肥的时间进行严格的控制。同时, 还要掌握施肥的方法, 确保施肥的方法 同水稻的发育情况具有良好适应性。施 肥的养分控制也很重要, 通过肥水配方 来把氮、钾、磷用肥的比例控制于 $2.1: 1.2: 1$, 以控制氮肥、科学追肥为原 则, 进行水稻的肥料选择时, 还要尽可能 地选用复合肥类型, 严禁在缓秧期间乱 追氮肥, 控制分繤中后期氮肥使用量, 防 止后期旺长和抽穗延迟, 提高结实率。

2. 4 抗病技术

2. 4 . 1 物理防治

在水稻种植中, 物理防治也是抗病 技术的一种类型, 目前, 有些地区通过太 阳能的照射技术来对水稻种子进行处理, 在经过太阳能的照射处理后的稻种, 不 仅能够有效地提高水稻抗寒以抗病害等 能力, 同时还能够促进种子发芽率的提 升, 提高水稻的产量; 同时, 通过静电处 理的技术, 来对水稻种子进行强烈电击 处理, 则会放出氮化物以及高浓度的臭 氧，而臭氧能够对种子具有杀菌消毒的 
作用, 对其黑穗头病的防治具有积极作 用。通过物理防治技术还能够进行水稻 种植害虫的防治, 其害虫防治的效果也 十分有效, 适用的范围比较广泛, 有能效 控制成本, 产生很好的经济效益, 如在水 稻虫害侵袭中, 在田间可以进行专用杀 虫灯的设置, 此类杀虫灯可以散发特殊 性的光波, 对害虫进行吸引后实施灭杀, 应用效果十分显著, 可以在田间设置相 应的杀菌消毒设施, 来对病害细菌进行 有效的消灭。

\section{4.2 生物防治}

生物防治技术是一种新型的现代化 抗病技术, 也是近年来一直重点研究的 技术类型。其中, 植物性杀菌技术就具有 很好的抗病效果, 通过光活化素借助植 物的次生物质于光照条件下, 对害虫以 及病菌等毒效的作用, 来实现对害虫以 及病菌的消灭, 将其制作光相应活化农 药类型, 在实现对病害消除的基础上, 还 不会对环境产生危害。印楝素, 是一种高 度氧化柠檬酸, 是从印楝的种子内分离 的活性物质类型, 有着杀虫的成分, 是理 想型杀虫的植物, 能够对大量昆虫有着 拒食绝育功效, 我国也是研制出了 $0.3 \%$ 浓度印楝素的乳油类型杀虫剂, 同时以 菌治菌的技术也具有很好的抗病效果， 其主要是借助微生物代谢过程产生抗生 素进行病菌的消灭, 这类抗生素包括赤 霉素、多抗的霉素以及春雷霉素等, 也逐 渐在农业种植中得到了应用。

生物防治的技术还能够大面积的实
现对水稻病害的防治, 在现阶段水稻病 害虫防治中, 比较常用生物防治的技术 就是引入害虫天敌的方式, 在水稻受到 白蛾的虫害时, 就可在稻田内引一些周 氏的啮小蜂, 在保证生态的平衡基础上, 来对白蛾进行有效杀灭, 还不会产生水 稻生长的负面影响。

\section{4.3 化学防治}

在进行水稻的病害防治阶段, 化学 防治的技术会对环境产生一定的影响， 因此, 要尽可能的避免化学药物应用, 若 必须借助农药, 就要进行用药次数以及 用药量的有效控制, 尽可能的选用一些 高效低毒的农药类型。当地病虫害常见 病包括稻瘟病、纹枯病等, 虫害有二化 螟、稻纵卷叶蛽、稻飞颯等, 应选择高效、 低毒、低残留的农药用于药物治疗, 以确 保控制和保护环境。例如, 在进行稻瘟病 防治中, 可使用 $20 \%$ 浓度 1000 倍液三环锉 的可湿类型粉剂实施喷酒; 对负泥虫可 使用 $3 \%$ 浓度阿维高氯的EC 兄水进行喷 酒; 对稻纹枯病防治, 在孕穗期间的病株 率达到了 $30 \%$ ～40\%时再进行施药, 且药 液要在稻株的中下部进行喷酒, 喷酒通 过泼浇法, 在田里要保持有 $3 \sim 5 \mathrm{~cm}$ 的浇 水层, 在进行井岗霉素使用时, 要尽可能 在雨后的晴天开展, 每 $667 \mathrm{~m} 2$ 使用 $5 \%$ 浓度 井岗霉素的水剂有 $150 \mathrm{~m} 1$, 或者使用井岗 需素的高浓度类型粉剂有 $25 \mathrm{~g}$, 以上任意 一种都要和 $100 \mathrm{~kg}$ 水进行兑和喷雾。

对于水稻的纵卷叶螟病害, 要重点 进行主害代的防治。在害虫低龄的幼虫
期, 其每百丛的水稻一般存在初卷的小 虫苞有 $15 \sim 20$ 个, 穗期的每百从存在幼 虫有 20 头时就可以进行施药, 每 $667 \mathrm{~m} 2$ 用 使用 $25 \%$ 浓度杀虫的双水剂与 150 $200 \mathrm{~mL}$, 或者使用 $50 \%$ 浓度杀蚯的松乳油 有 $72 \mathrm{~mL}$, 以上任何一种都要和 $60 \sim 72 \mathrm{~kg}$ 水进行兑和喷雾, 还可以兑水 $5 \sim 7.5 \mathrm{~kg}$ 进行低量的喷雾。其施药时间一般在傍 晚。同时还可以于穗期通过粉锈宁的新 技术进行病害防治, 水稻的孕穗期在每 $667 \mathrm{~m} 2$ 通过 $15 \%$ 浓度粉锈宁的可湿类型粉 剂有50 100g, 并兑水进行喷雾, 就能够 有效地避免杂交稻出现早衰情况, 同时 还能够实现对稻纹枯病以及稻曲病等病 害的防治。

\section{3 结束语}

在水稻种植中病害是影响其产量与 质量的主要因素, 为了保证其良好生产, 提高产品竞争力, 满足市场需求, 需要掌 握抗病技术的要点, 来做好对其病害的 防治, 这也是水稻种植中需要重点关注 的内容。

\section{[参考文献]}

[1]刘丽新.水稻种植中的抗病技术要 点分析[J].农民致富之友,2018(24):29-30.

[2]潘美兰.关于水稻种植中的 抗病技术要点的探讨 [J]. 农民致富之 友,2016(10):183.

[3] 邢广佳, 邢连江.水稻种植中 的抗病技术与实施要点探析[J].农技服 务,2017(4):64-65. 